\title{
Reliability Estimates For Power Supplies
}

\section{1st Symposium On Fusion Engineering}

\author{
Lee C. Cadwallader \\ Peter I. Petersen
}

September 2005

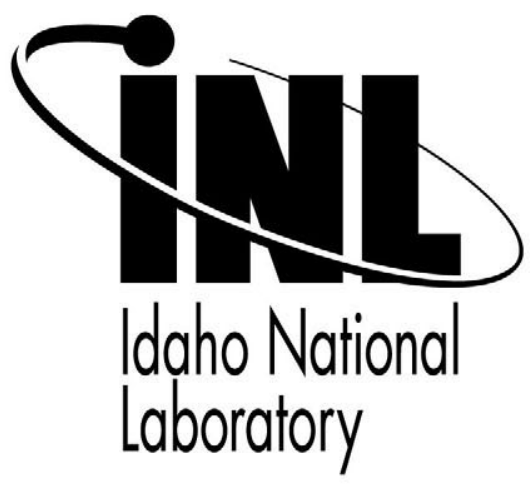

This is a preprint of a paper intended for publication in a journal or proceedings. Since changes may not be made before publication, this preprint should not be cited or reproduced without permission of the author. This document was prepared as an account of work sponsored by an agency of the United States Government. Neither the United States Government nor any agency thereof, or any of their employees, makes any warranty, expressed or implied, or assumes any legal liability or responsibility for any third party's use, or the results of such use, of any information, apparatus, product or process disclosed in this report, or represents that its use by such third party would not infringe privately owned rights. The views expressed in this paper are not necessarily those of the United States Government or the sponsoring agency. 


\title{
Reliability Estimates for Power Supplies
}

\author{
Lee C. Cadwallader, INL, and Peter I. Petersen, General Atomics
}

\begin{abstract}
This paper presents results of a task to analyze operating experience data to determine the combined 'fail to operate on demand' and 'fail to continue to run' failure rate for the toroidal field coil power supply at the DIII-D fusion facility. This large power supply is used in every plasma shot and has a considerable amount of operations data accumulated. Studying power supply reliability supports safety assessment, machine availability assessment and can potentially improve power supply performance. The DIII-D Trouble Report database was used to determine the number of power supply faults, system design descriptions supplied the power supply basic information, and operations data supplied the numbers of shots that have been performed. The power supply fail to operate failure rate was found to be 1.1E-02/operations hour. This reliability value compared well with the value from power supply data that has been analyzed from the Joint European Torus, and also compared very favorably with some particle accelerator power supply data.
\end{abstract}

\section{INTRODUCTION}

$\mathrm{T}$ International Energy Agency (IEA) sponsors a collaboration on the environmental, safety and economic aspects of magnetic fusion, and one of the tasks within the collaboration is development of a fusion component failure rate database. These data are to be used in quantifying probabilistic safety assessment, supporting traditional safety analysis, quantifying reliability availability maintainability inspectability analyses, and any other uses that field experience feedback can provide for fusion facilities. The failure rate database task has two parts. The first part of the task has been to collect or 'harvest' already-published data from high technology industries that can be readily applied to fusion components [1]. The second part of the task has been to collect and analyze operating experience data from existing tokamaks and other fusion experiments since many of these facilities have now accumulated significant time durations of operating experiences and documented these experiences to allow statistical data analysis. The data harvesting task initially populated a computerized database that has been developed and is currently operated at ENEA-Frascati [2]. The ongoing operating experience data analysis is providing further information to the database [3-6].

For the fusion-specific data collection and analysis from operating machines, it is prudent to compare the results to an independent data set to prove that the data are representative of other machine operating experiences, despite the soundness of data recording, collection, and analysis. By agreement among task participants, data values require some level of validation for entry into the database. Generally this validation is by comparison of two independent data values; good data compare within a factor of 3 , fair data within a factor of 10, and poor data compare at larger than a factor of 10 [1]. Positive comparisons demonstrate that the values are actual rates and not the result of some site-specific issue. Developing a second, independent data set for validation comparison is difficult. Task participants endeavor to develop data sets that are complimentary for the purpose of validation. The data presented here are the initial results of a task to generate an independent data set from DIII-D operating experiences to compare to similar work that has been completed on operating experiences from the JET Joint Undertaking [7].

The large power supplies have been chosen for study since this type of component will be needed for the International Thermonuclear Experimental Reactor (ITER) and other future experiments. While the power supplies for DIII-D's resistive magnets are not similar to ITER superconducting magnet power supplies, the electrical energy delivered by DIII-D power supplies makes them relevant to other ITER uses and the magnet power supply operating experiences are valuable feedback for future experiments that require any type of large power supplies. Large power supplies all tend to have fairly high currents and/or voltages and thus pose operational safety concerns; DIII-D personnel are excluded from the power supply areas during operations as a safety precaution. Any faults in this high-energy equipment are important to understand for operational safety and machine availability.

\section{DIII-D OPERATING EXPERIENCE DATA ANALYSIS}

The DIII-D experiment has twenty-four toroidal field (TF) magnets. Applying $127 \mathrm{kA}$ to these water-cooled copper coils gives a maximum magnetic field of $2.2 \mathrm{~T}$ on axis. There are four modules in the TF power supply, which is designated as the "B" power supply (PS). Two modules are operated two and two in parallel and the two sets are in series; they are connected by interphase transformers and output busbars. The modules are powered by $13.8 \mathrm{kVac}, 525$ MVA input power from one of the on-site motor-generator sets. Each power supply module supplies $500 \mathrm{Vdc}$ at $65 \mathrm{kA}$, producing a total output of $1000 \mathrm{Vdc}$ at $130 \mathrm{kA}$. All four modules combined weigh a total of 168 metric tons, and require air cooling to the transformers and water cooling to the rectifiers [8]. 
The B PS ramps up the TF coil current to a pre-programmed value for a given plasma shot over $\sim 4.5 \mathrm{~s}$ before the plasma shot. The four modules regulate the coil flattop current for up to $5 \mathrm{~s}$, and overcome the resistive losses in the coil and buswork. Then the PS ramps down over $\sim 1 \mathrm{~s}$ [8]. The power supplies and magnet coils then cool down for $\sim 10$ minutes and can then be set to pulse again. The modules use 'hockey puck' silicon controlled rectifiers (SCRs) for secondary rectification and output current control. Each module has its own circuit breaker and is individually protected. Each of the four TF PS modules has a separate control cabinet with interlocks and current regulation circuitry.

The TF PS is used for each plasma operation while other power supplies dedicated to plasma heating may be idle, depending on the physics parameters needed for a given plasma shot. Therefore, the total count of plasma shots give the operational demands of the TF magnet PS. Table 1 gives the annual count of plasma shots and operating days.

Table 1. Annual Counts of DIII-D Plasma Shots

\begin{tabular}{|l|l|}
\hline Operating Year & $\begin{array}{l}\text { Number of Plasma Shots } \\
\text { and Operating Days }\end{array}$ \\
\hline 1987, May 19 to end of year & 2,265 in 63 days from May \\
\hline 1988 & 3,358 in 105 days \\
\hline 1989 & 3,953 in 121 days \\
\hline 1990 & 1,829 in 62 days \\
\hline 1991 & 2,617 in 99 days \\
\hline 1992 & 1,514 in 56 days \\
\hline 1993 & 2,362 in 87 days \\
\hline 1994 & 1,976 in 65 days \\
\hline 1995 & 1,725 in 59 days \\
\hline 1996 & 1,788 in 59 days \\
\hline 1997 & 1,823 in 77 days \\
\hline 1998 & 1,511 in 55 days \\
\hline 1999 & 1,914 in 72 days \\
\hline 2000 & 2,239 in 78 days \\
\hline 2001 & 3,045 in 96 days \\
\hline 2002 & 2,241 in 87 days \\
\hline 2003 & 3,425 in 128 days \\
\hline 2004 & 3,589 in 131 days \\
\hline Totals & 43,174 in 1,500 days \\
\hline note: Operations are 0630 to 2200 hours, or 15.5 -hour days \\
\hline
\end{tabular}

The shots listed in Table 1 are actual plasma attempts. Not every shot satisfies its engineering or physics parameters, but in all of these cited shots the B PS was demanded to operate. Operating days were counted to provide comparison to the data analysis results for the JET power supplies.

Starting up after a long tokamak outage can pose a reliability concern for large power supplies. Both particle accelerators and fusion experiments $[9,10]$ have noted that the power supplies do not operate well for the day or two after an extended outage of a week or longer. DIII-D data have not yet been analyzed at such a level of detail to affirm or refute this experience, but DIII-D staff routinely test the power supplies before machine restart to enhance PS reliability. This testing usually requires two weeks during long outages due to the number of power supplies needed to operate the plasma confinement and heating systems.

The DIII-D Trouble Report Database [11] was used to provide the B PS fault reports. Between the database inception in May 1987 and the end of 2004, there were 275 trouble reports (TRs) for the B PS. These reports are too numerous to recreate in this paper. The TRs are summarized in Table 2 , listed by the affected subcomponents.

Table 2. DIII-D Trouble Report Counts from 1987 - 2004

\begin{tabular}{|l|c|c|}
\hline Component & Number of TRs & Downtime (h) \\
\hline SCRs & 90 & 81.20 \\
\hline Gate drive boards & 22 & 46.00 \\
\hline Circuit breakers & 48 & 28.75 \\
\hline $\begin{array}{l}\text { Other } \\
\text { components }\end{array}$ & 115 & 68.15 \\
\hline Total & 275 & 224.10 \\
\hline
\end{tabular}

The reliability analysis work performed for the coil power supplies on the JET machine used two failure modes [7]. The first failure mode was 'alarm/erratic alarm/fail to preset' and the second failure mode was 'fail to operate/spurious operation'. The present work for DIII-D used different terminology but the failure modes are similar and align to allow comparison. The DIII-D data showed few erratic alarms and only a few events of failure to preset the PS before a shot. The DIII-D data showed mainly power supply failure to operate (FTO), where the power supply had been prepared but did not begin to supply power to the magnet set, and failure to continue to run (FTCTR), where the power supply began to operate but did not operate for the entire pulse. The data also showed a few events of PS improper operation, Where the PS operated but did not provide the requested power. Improper operation failures were combined with FTCTR and FTO failures for comparison to the $\mathrm{FTO}$ /spurious operation portion of the JET data analysis results. Table 3 gives the results of the data binning for DIII-D TRs.

The data in Table 3 do not sum to equal the number count of PS TRs. This is because some TRs describe failures that were not attributable to the PS itself, and some TRs cited either multiple events of the B PS not operating for several sequential plasma shots or described PS output troubles that occurred over several shots. Table 4 gives the TF coil PS system failure rates and the JET coil PS values. 
Table 3. DIII-D Trouble Report Data Analysis Results

\begin{tabular}{|c|c|c|}
\hline Component & Failure Modes & TR Count \\
\hline \multirow[t]{7}{*}{ SCRs } & FTO & 68 \\
\hline & FTCTR & 22 \\
\hline & Improper Operation & 0 \\
\hline & No Failure & 1 \\
\hline & Fail to Preset & 0 \\
\hline & Alarm & 0 \\
\hline & Erratic Alarm & 0 \\
\hline \multirow[t]{7}{*}{ Gate drive boards } & FTO & 9 \\
\hline & FTCTR & 7 \\
\hline & Improper Operation & 4 \\
\hline & No Failure & 2 \\
\hline & Fail to Preset & 1 \\
\hline & Alarm & 0 \\
\hline & Erratic Alarm & 0 \\
\hline \multirow[t]{7}{*}{ Circuit breakers } & FTO & 38 \\
\hline & FTCTR & 4 \\
\hline & Improper Operation & 0 \\
\hline & No Failure & 3 \\
\hline & Fail to Preset & 2 \\
\hline & Alarm & 0 \\
\hline & Erratic Alarm & 1 \\
\hline \multirow{7}{*}{$\begin{array}{l}\text { Other } \\
\text { components }\end{array}$} & FTO & 29 \\
\hline & FTCTR & 54 \\
\hline & Improper Operation & 16 \\
\hline & No Failure & 19 \\
\hline & Fail to Preset & 3 \\
\hline & Alarm & 2 \\
\hline & Erratic Alarm & 8 \\
\hline
\end{tabular}

\section{DISCUSSION}

The collected DIII-D experiences dwelled on component failures that precluded operations rather than alarm conditions. That emphasis is expected because the motivating reason for the Trouble Report database is to convey information from the operations personnel to the maintenance personnel [11]. Efficient communications allow the machine to be promptly repaired and thus increase its operational availability. Some of the JET data originated from a similar trouble report system and some came from operations logbooks. Thus, the logs gave a higher level of alarm reporting in the JET data. The differences between data sets available for analysis is believed to be one reason for the rather wide (factor of $\sim 50$ ) discrepancy between the 'alarm and fail to preset' failure rates in Table 4. The 'FTO and spurious operation' values for JET and DIII-D compared much more closely, within a factor of 3 of each other. One reason for the difference in the hardware failure rates could be that the JET power supplies are larger than the DIII-D power supplies. A larger PS has more components that could fail, such as SCRs, and this may be the primary reason why the JET PS FTO failure rate is greater
Table 4. DIII-D and JET Coil PS Failure Rate Results

\begin{tabular}{|c|c|c|c|c|}
\hline $\begin{array}{l}\text { Facility } \\
\text { and } \\
\text { Failure } \\
\text { Mode }\end{array}$ & $\begin{array}{c}\text { System } \\
\text { Failure } \\
\text { Count }\end{array}$ & $\begin{array}{c}\text { System } \\
\text { Operating } \\
\text { Time } \\
\text { (h) }\end{array}$ & $\begin{array}{l}\text { Average } \\
\text { Failure } \\
\text { Rate } \\
\text { (/h) }\end{array}$ & $\begin{array}{l}\text { Upper } \\
\text { Bound } \\
\text { Failure } \\
\text { Rate } \\
\text { (/h) }\end{array}$ \\
\hline $\begin{array}{l}\text { DIII-D } \\
\text { Alarm and } \\
\text { Fail to } \\
\text { Preset }\end{array}$ & 17 & 23,250 & $7.3 \mathrm{E}-04$ & $1.1 \mathrm{E}-03$ \\
\hline $\begin{array}{l}\text { JET } \\
\text { Alarm and } \\
\text { Fail to } \\
\text { Preset }\end{array}$ & 534 & 14,864 & $3.6 \mathrm{E}-02$ & $3.9 \mathrm{E}-02$ \\
\hline $\begin{array}{l}\text { DIII-D } \\
\text { FTO and } \\
\text { Spurious } \\
\text { Operation }\end{array}$ & 251 & 23,250 & $1.1 \mathrm{E}-02$ & $1.2 \mathrm{E}-02$ \\
\hline $\begin{array}{l}\text { JET } \\
\text { FTO and } \\
\text { Spurious } \\
\text { Operation }\end{array}$ & 456 & 14,864 & $3.1 \mathrm{E}-02$ & $3.3 \mathrm{E}-02$ \\
\hline
\end{tabular}

than the DIII-D failure rate. Overall, FTO relates more directly to the PS hardware than the Alarm failure mode, and per the IEA data convention described earlier, the FTO comparison was very positive. This close comparison suggests that these two data sets can be used to validate each other for hardware faults and that further analysis work is warranted.

PS operating experiences from particle accelerators show similar trends to the DIII-D and JET experiences. The Advanced Photon Source PS's had a four-year average FTO failure rate of $1 \mathrm{E}-02 / \mathrm{h}$ [10] for mature components, which is highly comparable to the data given in Table 4. The DAФNE accelerator reported between 0.18 and 0.36 power supply faults per operating day with an average value of 0.32 [9], this rate is within the range of the DIII-D and JET experience.

The JET data overall showed that these power supplies are a challenge to operate. There was an average of 1.2 troubles per operating day for the set of JET coil power supplies [7]. The DIII-D average was 0.18 troubles per operating day for the TF coil PS. The variation between these TR rates is believed to be due to JET data including larger PS's, more coil PS units, and more alarm data than the presently evaluated DIII-D TF PS data set. While the DIII-D TR rate is only $15 \%$ of the JET value, the DIII-D rate still poses operational inconvenience.

The DIII-D data has also presented some qualitative safety information in the form of a small number of events of plant safety importance. Out of the 275 TRs, there were two events of battery failures in the B PS uninterruptible power supplies. 
These events, in 1987 and 1989, involved failed batteries overheating, which resulted in smoke that actuated smoke detectors and also a limited amount of flames. The staff responded and extinguished the fires. A 1993 TR described a small amount of sparks issuing from the side of module 1 of the B PS during pulse shots; the module was cited for repair in the pending outage. In another TR from 1998, an SCR in PS module 2 failed catastrophically, spewing hot debris that caused collateral damage to nearby components. DIII-D has experienced dozens of SCR failures in the B PS, and there are more TRs that cite SCR failures in other power supplies. In general, SCRs tend to fail benignly rather than by disassembling and scattering hot debris and ionized air. While rare, SCR failures that lead to fire or disassembly are known to occur. Melvold [12] presented data that an operational failure rate for power routing thyristor SCRs was $0.5 \%$ per plant year, averaged over 20 utilities for 14 years. Few of those faults led to fires. Further work on DIII-D PS data will be needed to confirm if tokamaks experience a similar failure rate. A notable event occurred at DIII-D in 1998 - a staff member reported a foul smell emanating from the B PS. Investigation revealed it was merely an odor from nylon screws in the PS warming up; nonetheless, this event demonstrates the high level of attention the staff gives to tokamak operation. Overall, the TRs serve to illustrate that the PS controls a large amount of electrical energy and that DIII-D's safety measures to set up exclusion areas around these units during operations is prudent to protect personnel from rare SCR failure events and other electrical faults. Another qualitative observation from the data set is that some mechanical parts, notably circuit breakers, have definite useful lifetimes and repeated exercising leads to excessive wear and early failure; this has been noted in fusion and accelerators $[13,14]$. Despite the fact that DIII-D is approaching its twentieth anniversary, some PS components remain state-ofthe-art for the function they provide and some failures should be expected. In addition, because of the high frequency of troubles, there is a fairly high amount of troubleshooting, maintenance, and parts replacement activity noted with this PS. Proper electrical safety procedures must be followed to assure that the staff is protected from electrical injury. DIII-D has had a good electrical and industrial safety record, as seen in its annual reports, and the practices [15] that result in these good operations must be carried forward to ITER.

\section{CONCLUSIONS}

This paper has presented an overall field experience failure rate for the TF coil PS at DIII-D. The results for failure to operate compared well to the JET PS operating experience history, and there was very good agreement with published data from a particle accelerator as well. Future work in this area of operating experience review feeding forward to future machines will include analysis of additional data on the other DIII-D power supply systems and individual components in those systems to complete the comparison with the data obtained from JET. When further work has been completed, more detailed comparisons can be made to validate the data for inclusion into the IEA failure rate database.

\section{ACKNOWLEDGMENTS}

The analysis presented here could not have been performed without the aid of the DIII-D operations staff, who have collected the operations data and maintain the Trouble Report database. This work was prepared for the US Department of Energy (DOE), Office of Fusion Energy Sciences, under the DOE Idaho Field Office contract number DE-AC07-05ID14517 and US DOE contract DE-AC03-99ER54463 with General Atomics. This paper is also identified as INL/CON-05-00271.

\section{REFERENCES}

[1] L. Cadwallader and T. Pinna, "Progress Toward a Component Failure Rate Data Bank for Magnetic Fusion Safety," Proceedings of the International Topical Meeting on Probabilistic Safety Assessment (PSA '99), Washington DC, Aug. 22-26, 1999, ANS (1999) 11-17.

[2] T. Pinna and L. Cadwallader, "Component Failure Rate Data Base for Fusion Applications," Fusion Engineering and Design, 51-52 (2000) 579-585.

[3] T. Pinna, J. Izquierdo, M. T. Porfiri, and J. Dies, "Fusion Component Failure Rate Database (FCFR-DB)," paper 07-339, presented at the $7^{\text {th }}$ International Symposium on Fusion Nuclear Technology, Tokyo, Japan, May 22-25, 2005.

[4] T. Pinna, G. Cambi, A. Lo Bue, C. Rizzello, Collection and Analysis of Data Related to Fusion Machines (JET and TLK) Operation Experience on Component Failures, FUS-TN-SA-SE-R-058, Associazione ENEA-EURATOM sulla Fusione (February 2003).

[5] L. C. Cadwallader and P. I. Petersen, "Reliability Estimates for Oxygen Monitors," Proceedings of the $20^{\text {th }}$ Symposium on Fusion Engineering, San Diego, CA, October 14-17, 2003, IEEE (2003), 171174.

[6] L. C. Cadwallader and P. I. Petersen, "Confinement Reliability Estimates for Vacuum System Components," Fusion Science and Technology, 44 (2003) 382-387

[7] T. Pinna, F. Gravanti, G. Cambi, P. Polinari, JET Data Collection on Component Malfunctions and Failure of Neutral Injectors and Power Supply Systems, FUS-TN-SA-SE-R-121, Associazione ENEAEURATOM sulla Fusione (December 2004).

[8] System Design Description of DIII-D, GA-A19264, General Atomics, (1989).

[9] M. Incurvati et al., "DAФNE Power Supply System: 5 years of Experience and Statistics," Proceedings of the $8^{\text {th }}$ European Particle Accelerator Conference (EPAC '02), Paris, France, June 3-7, 2002, CERN (2002) 2478-2480.

[10] A. Hillman, J. Carwardine, and G. Sprau, "Magnet Power Supply Reliability at the Advanced Photon Source," Proceedings of the 2001 Particle Accelerator Conference (PAC 2001), Chicago, Illinois, June 18-22, 2001, IEEE (2001) 3657-3659.

[11] P. I. Petersen and S. M. Miller, "The DIII-D Tokamak Trouble Report Database," Proceedings of the $14^{\text {th }}$ IEEE/NPSS Symposium on Fusion Engineering, San Diego, CA, Sept. 30 - Oct. 3, 1991, IEEE (1991) 776-778.

[12] D. J. Melvold, "HVDC Converter Terminal Maintenance/Spare Parts Philosophy and Comparison with Performance," IEEE Transactions on Power Delivery, 7 (1992) 869-875.

[13] N. L. Greenough, C. L. Neumeyer, and D. Nayberry, "TFTR Energy Conversion System: Reliability in the Real World," Proceedings of the $12^{\text {th }}$ Symposium on Fusion Engineering, Monterey, CA, October 1216, 1987, IEEE (1987) 432-435.

[14] D. Wolff, H. Pfeffer, "Experience in Maintaining and Operating Power Supplies Used in Accelerators," Proceedings of the $5^{\text {th }}$ European Particle Accelerator Conference (EPAC '96), Sitges, Spain, June 1014, 1996, Taylor \& Francis (1996) 2337-2339.

[15] P. I. Petersen et al., DIII-D Safety Procedures and Operational Experience, GA-A19687, General Atomics (June 1989). 